\title{
Where is smoking research published?
}

\author{
Anthony Liguori, John R Hughes
}

\begin{abstract}
Objective - To identify journals that have a focus on human nicotine/smoking research and to investigate the coverage of smoking in "high-impact" journals.

Design-The MEDLINE computer database was searched for English-language articles on human studies published in 1988-1992 using "nicotine", "smoking", "smoking cessation", "tobacco", or "tobacco use disorder" as focus descriptors. This search was supplemented with a similar search of the PSYCLIT computer database. Fifty-eight journals containing at least 20 nicotine/smoking articles over the five years were analysed for impact factor (IF; citations per article).
\end{abstract}

Results-Among the journals with the highest percentage of nicotine- or smoking-focused articles (that is, 9-39\% of their articles were on nicotine/ smoking), Addiction, American Journal of Public Health, Cancer Causes and Control, Health Psychology, and Preventive Medicine had the greatest IF (range = 1.3-2.6). Among the journals highest in impact factor (IF $>3$ ), only American Journal of Epidemiology, American Review of Respiratory Disease, Journal of the National Cancer Institute, and Journal of the American Medical Association published more than 10 nicotine/ smoking articles per year (3-5\% of all articles). Of these, only Journal of the American Medical Association published a large number of nicotine/smoking articles (32 per year).

Conclusions - Although smoking causes $20 \%$ of all mortality in developed countries, the topic is not adequately covered in high-impact journals. Most smoking research is published in low-impact journals.

(Tobacco Control 1996; 5: 37-38)

Keywords: smoking research, citations

Human Behavioral Pharmacology Laboratory, Department of Psychiatry, University of Vermont, Burlington, Vermont 05401, USA A Liguori J R Hughes

Correspondence to: John R Hughes, Human Behavioral Pharmacology Laboratory, Department of Psychiatry, University of Vermont, Burlington, Vermont 054011419 , USA.

\section{Introduction}

Although smoking causes $20 \%$ of all mortality in developed countries, ${ }^{1}$ only four journals International Fournal of Smoking Cessation, Fournal of Smoking-related Disorders, Tobacco Control, and World Smoking and Health-

This paper was presented at the annual meeting of the American Psychological Association, New York, NY, in August 1995; and a few key findings were cited in the Summer/Fall 1995 issue of the Society for Research on Nicotine and Tobacco Newsletter.

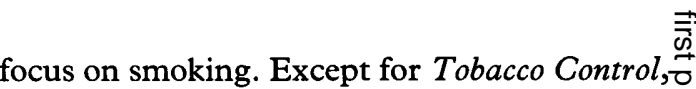
thesejournals are publishedinfrequently (quart-듬 erly or less) and publish few articles per issue (usually fewer than 10). None were listed in $\frac{\mathbb{Q}}{\varrho}$ Index Medicus in 1995.

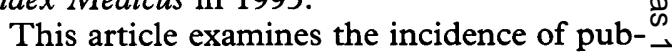
lishing on nicotine and smoking among dif-. ferent journals. If a relatively high percentage $\vec{\omega}$ of articles in a journal are focused on nicotine $/ \stackrel{\Omega}{\sim}$ smoking, one may infer that the journal's? editors, reviewers, and readers have a high:degree of interest in such research. We alsow examined the prestige of the journals thato publish nicotine/smoking articles. We defined "prestige" in terms of the journal's impact 3 factor $(\mathrm{IF})^{2}-$ that is, the average number of $\frac{2}{0}$ citations per published article. Finally, we $\stackrel{\mathcal{J}}{ }$ examined how often nicotine/smoking articles $\overrightarrow{0}$ appear in high-impact journals.

\section{Methods}

We searched the MEDLINE computer database for nicotine/smoking articles during the five- $\mathbb{\perp}$ year period 1988 to 1992 . Although the US $\overrightarrow{\vec{A}}$ Centers for Disease Control and Prevention's 3 Smoking and Health Database might seem? more appropriate, we chose MEDLINE because it limited our search to human-related studies, to more specific descriptors (see below), and to articles in which nicotine/smoking was the primary focus. MEDLINE also allowed us to exclude letters to the editor.

The search was limited to English-languageō references with human subjects and used theo index terms "nicotine", "smoking", "smoking cessation", " tobacco", or "tobaccoᄋ use disorder" as descriptors of the article's focus. For brevity, we will refer to all such articles as "smoking-focused".

In an attempt to find behavioural/social science journals that publish smoking research but are not indexed in MEDLINE, we conducteo a similar search of the American Psychologican Association's PSYCLIT database using the focus $\omega$ descriptors "nicotine", "smokeless tobacco", "smoking cessation", and " tobacco smoking "율

The MEDLINE search produced 4857\% smoking-focused articles. The 56 journalso containing at least 20 such articles represented $48 \%$ of all smoking-focused articles. We analysed journals containing at least 20 such $\overrightarrow{\mathfrak{Z}}$ citations (an average of four articles per year for the average number of smoking-focuseo references per year during the five-year period? average number of articles per year (as selectedi by MEDLINE), percentage of all articles that were focused on smoking, and average annual IF. ${ }^{3,4}$ fournal Citation Reports does not report IF for monographs, several annual publications, and recently created journals (for 
Table 1 fournals in which more than $5 \%$ of articles were on nicotine/smoking, 1988-1992

\begin{tabular}{|c|c|c|}
\hline fournal & $\begin{array}{l}\text { Mean percentage of } \\
\text { articles on smoking/year } \\
\text { (smoking/total) }\end{array}$ & $\begin{array}{c}\text { Mean } \\
\text { impact } \\
\text { factor }\end{array}$ \\
\hline $\begin{array}{l}\text { Addict Behav } \\
\mathcal{F} \text { Subst Abuse } \\
\text { Prev Med } \\
\text { Addiction } \\
\text { Cancer Causes Control } \\
\text { Health Psychol } \\
\mathcal{F} \text { Behav Med } \\
\text { Am } \mathcal{f} \text { Prev Med } \\
\text { Monogr Natl Cancer Inst } \\
\mathcal{F} \text { Psychoactive Drugs } \\
\text { Am } \mathcal{F} \text { Public Health } \\
\text { Epidemiology } \\
\text { Int } \mathcal{F} \text { Epidemiol } \\
\text { Int } \mathcal{F} \text { Addict } \\
\text { Can } \mathcal{F} \text { Public Health } \\
\mathcal{F} \text { Sch Health } \\
\mathcal{F} \text { Epidemiol Commun Health } \\
\mathcal{F} \text { Consult Clin Psychol }\end{array}$ & $\begin{array}{c}39(25 / 64) \\
32(8 / 25) \\
25(17 / 68) \\
15(27 / 176) \\
14(4 / 31) \\
14(8 / 58) \\
13(6 / 42) \\
13(9 / 70) \\
12(5 / 42) \\
10(5 / 50) \\
9(28 / 303) \\
8(4 / 52) \\
7(12 / 171) \\
7(7 / 98) \\
7(7 / 110) \\
6(5 / 83) \\
6(5 / 77) \\
6(7 / 122)\end{array}$ & $\begin{array}{l}0.9 \\
\mathrm{nc} \\
1.4 \\
1.3 \\
1.4 \\
1.8 \\
1.1 \\
0.7 \\
\mathrm{nc} \\
0.6 \\
2.6 \\
\mathrm{nc} \\
1.3 \\
0.5 \\
0.4 \\
0.6 \\
1.4 \\
2.5\end{array}$ \\
\hline
\end{tabular}

$\mathrm{nc}=$ Not covered by fournal Citation Reports.

Table 2 fournals with an average annual impact factor of 2.7 or more, that published a mean of four or more articles per year on nicotine/smoking research, 1988-1992

\begin{tabular}{lcc}
\hline fournal & $\begin{array}{c}\text { Mean percentage of } \\
\text { articles on smoking/year } \\
\text { (smoking/total) }\end{array}$ & $\begin{array}{c}\text { Mean } \\
\text { impact } \\
\text { factor }\end{array}$ \\
\hline N Engl f Med & $1(5 / 574)$ & 22.7 \\
Lancet & $1(6 / 853)$ & 15.2 \\
F Natl Cancer Inst & $3(11 / 325)$ & 5.3 \\
FAMA & $3(32 / 997)$ & 5.3 \\
Am Rev Respir Dis & $3(17 / 547)$ & 4.8 \\
Cancer Res & $1(6 / 1183)$ & 4.6 \\
MMWR & $5(10 / 203)$ & 3.6 \\
BMF & $1(10 / 917)$ & 3.2 \\
Clin Pharmacol Ther & $3(5 / 168)$ & 3.2 \\
Am F Epidemiol & $5(13 / 261)$ & 3.0 \\
Int $\mathcal{F}$ Cancer & $2(7 / 397)$ & 2.9 \\
Arch Intern Med & $2(6 / 338)$ & 2.8 \\
Carcinogenesis & $1(5 / 391)$ & 2.7 \\
Psychopharmacology (Berl) & $5(15 / 298)$ & \\
\hline
\end{tabular}

example, Advances in Experimental Medicine and Biology, Epidemiology, fournal of Substance Abuse, Monographs of the National Cancer Institute, NID $A$ Research Monograph, Nursing Times, and Progress in Clinical and Biological Research). We designated journals in which more than $5 \%$ of the articles were smokingfocused as the "high-smoking-focus group", and the 14 journals with the greatest mean impact factor as the "high-impact group".

\section{Results}

The 18 high-smoking-focus journals (table 1) and the 14 high-impact journals (table 2) were mutually exclusive. Within the high-smokingfocus group, American Fournal of Public Health, Addiction, and Addictive Behaviours contained the greatest number of smokingfocused articles (range $=25-28$ articles per year). Among the 12 journals with the highest percentage of smoking-focused articles, American Fournal of Public Health, Health Psychology, Cancer Causes and Control, Preventive Medicine, and Addiction had the greatest IF (range $=1.3-2.6$ ). Only two highsmoking-focus journals, American fournal of Public Health and Fournal of Consulting and Clinical Psychology, had an IF greater than 2.

Among high-impact journals, Fournal of the American Medical Association ( $\mathcal{F} A M A)$ (IF = 5.3) published the highest number of smoking- focused articles (mean $=32$ per year), and American Fournal of Epidemiology (IF = 3.2), MMWR Morbidity and Mortality Weekly Report (IF = 4.6), and Psychopharmacology $(\mathrm{IF}=2.7)$ published the highest percentage $(5 \%)$ of smoking-focused articles. Other highimpact journals (British Medical fournal, Cancer Research, Lancet, Clinical Pharmacology and Therapeutics, and New England fournal of Medicine) published only 5-10 smoking-focused articles per year (1-3\%).

The supplementary PSYCLIT search produced two journals not indexed by MEDLINE: Health Education Research and American Fournal of Health Promotion. The former averaged eight smoking-focused articles out of 41 articles annually $(22 \%)$ and the latter averaged six smoking-focused articles out of 25 articles annually (24\%). Fournal Citation Reports did not provide impact factors for either of these journals. Although these figures would suggest that these two journals would rank among the top five high-focus journals, the figures for total number of articles from MEDLINE and PSYCLIT are not comparable, that is, PSYCLIT typically selects fewer articles for coverage than MEDLINE does. Thus, the numerator and the denominator for "focus" percentages differ between MEDLINE and PSYCLIT.

\section{Discussion}

Although smoking causes $20 \%$ of all mortality in developed countries, ${ }^{1}$ except for $\mathcal{F} A M A$, smoking research is barely represented in highimpact general medical journals such as Annals of Internal Medicine, British Medical Fournal, Lancet, or New England Fournal of Medicine, or science journals such as Nature or Science. In fact, high smoking focus and high impact were mutually exclusive.

Several journals devoted a relatively high proportion of their space to smoking research but had low impact factors. The exceptions were Addiction, American fournal of Public Health, and Preventive Medicine, which had a high number and proportion of smoking articles and relatively high impact factors.

Conversely, other journals had high impact but devoted a very small proportion of space to smoking. The exceptions here were $\mathscr{f} A M A$ and, to a lesser degree, American Fournal of Epidemiology, American Review of Respiratory Disease, and Psychopharmacology. These journals had high impact factors yet also published many smoking-focused articles.

This study was supported by Research Scientist Development Award K02 00109 from the National Institute on Drug Abuse.

1 Peto R, Lopez AD, Boreham J, Thun M, Heath Jr C. Mortality from tobacco in developed countries: indirect estimation from national vital statistics. Lancet 1992; 339: $1268-78$.

2 Garfield E. Citation analysis as a tool in journal evaluation. Science 1972; 178: 471-9.

3 Garfield E. SCI journal citation reports; a bibliometric analysis of science journals in the ISI database. Philadelphia, Pennsylvania: Institute for Scientific Information, Inc., 1989-1993.

4 Garfield E. SSCI journal citation reports; a bibliometric analysis of science journals in the ISI database. Philadelphia, Pennsylvania: Institute for Scientific Information, Inc., 1989-1993. 